\title{
Distribution Analysis of TRISO-Coated Particles in Fully Ceramic Microencapsulated Fuel Composites
}

\author{
Hyeon-Geun Lee*,, Daejong Kim*, Seung Jae Lee**, Ji Yeon Park*, and Weon-Ju Kim* \\ *Nuclear Materials Development Division, Korea Atomic Energy Research Institute, Daejeon 34057, Korea \\ **Materials Development Section, KEPCO Nuclear Fuel, Daejeon 34057, Korea
}

(Received June 8, 2018; Accepted June 18, 2018)

\begin{abstract}
FCM nuclear fuel, a concept proposed as an accident tolerant fuel in light water reactors, consists of TRISO fuel particles embedded in a SiC matrix. The uniform dispersion of internal TRISO fuel particles in the FCM fuel is very important for improving the fuel efficiency. In this study, FCM sintered pellets with various volume ratios of TRISO-coated particles were prepared by hot press sintering. The distribution of TRISO-coated particles was quantitatively analyzed using X-ray $\mu \mathrm{CT}$ and expressed as a dispersion uniformity index. TRISO-coated particles were most uniformly dispersed in the FCM pellets prepared using only overcoated TRISO particles without mixing of additional SiC matrix powder. FCM pellets with uniformly dispersed TRISO particle volume fraction of up to $50 \%$ were prepared using overcoated TRISO particles with varying thickness.
\end{abstract}

Key words : FCM fuel, TRISO, SiC, Distribution

\section{Introduction}

$\mathbf{F}$ ully ceramic microencapsulated (FCM) nuclear fuel is a concept that was proposed as an accident tolerant fuel in light water reactors. FCM nuclear fuel is composed of TRi-ISOtropic (TRISO)-coated nuclear fuel particles used as the nuclear fuel of very high temperature reactors (VHTRs) dispersed in a high density $\mathrm{SiC}$ (Silicon Carbide) matrix. ${ }^{1-3)}$ The TRISO nuclear fuel particles dispersed within the FCM nuclear fuel are structured to protect the $\mathrm{UO}_{2}$ kernel with a $\mathrm{PyC} / \mathrm{SiC} / \mathrm{PyC}$ triple layer. The $\mathrm{SiC}$ layer of the TRISO particles is fabricated using chemical vapor deposition (CVD), and this $\mathrm{SiC}$ layer prevents the fission products within the nuclear fuel particles from being transferred to the outside and maintains the structural integrity of the TRISO particles under high temperatures. ${ }^{4)}$ The SiC matrix phase surrounding the TRISO particles is fabricated through sintering, protects the TRISO particles from the external environment, and provides double protection so that the fission products produced internally do not escape. The FCM nuclear fuel can be expected to provide rapid improvement in accident tolerance due to its high thermal conductivity, multiple protection regarding fission products, and very high temperature stability. $\mathrm{SiC}$ ceramics are being utilized in various nuclear energy fields due to their outstanding high temperature strength, chemical stability, and irradiation resistance along with a low neutron absorption cross section. ${ }^{5-7)} \mathrm{SiC}$ exhibits high thermal conductivity compared

\footnotetext{
${ }^{\dagger}$ Corresponding author: Hyeon-Geun Lee

E-mail : hglee@kaeri.re.kr

Tel : +82-42-866-6090 Fax : +82-42-868-8549
}

to that of $\mathrm{UO}_{2}$, and thus the use of $\mathrm{SiC}$ as the matrix phase of the nuclear fuel pellets can decrease the temperature at the nuclear fuel center compared to a $\mathrm{UO}_{2}$ nuclear fuel system, resulting in a decrease of the internal energy and release of the fission products. ${ }^{8)}$

$\mathrm{SiC}$ ceramics are manufactured using the liquid-phase sintering by generally adding metal oxide additives due to the strong covalent bonding property and low self diffusion coefficient. Hot press sintering is one of the most effective methods of fabricating $\mathrm{SiC}$ composite ceramics that include different secondary phases., ${ }^{910}$ There have been numerous reports of fabricating fiber-reinforced $\mathrm{SiC}$ composites composed of $\mathrm{SiC}$ fibers and $\mathrm{SiC}$ matrix phases through hot press sintering. ${ }^{11,12)}$ FCM nuclear fuel contains TRISO particles, which do not undergo deformation including contraction, and therefore FCM nuclear fuel is manufactured using hot press sintering. There have been reports of results of FCM pellet fabrication by adding $\mathrm{Al}_{2} \mathrm{O}_{3}, \mathrm{Y}_{2} \mathrm{O}_{3}$, and nano-sized $\mathrm{SiC}$ powder, and studies have been conducted on the densification and thermal conductivity of FCM pellets according to the TRISO particle and sintering additive amounts. ${ }^{13-15)}$

When using FCM nuclear fuel as the nuclear fuel of light water reactors, it is important to add a large amount of TRISO particles to the $\mathrm{SiC}$ matrix phase in order to increase the power generation efficiency. Dense fabrication of FCM pellets containing a maximum of 46 vol.\% TRISO particles through hot press sintering has been reported. ${ }^{13)}$ In order to uniformly distribute a large amount of TRISO particles in the FCM pellet matrix phase, the TRISO particles can be overcoated using $\mathrm{SiC}$ matrix phase powder. Overcoating of the TRISO particles can prevent damage of the TRISO coating layer when the TRISO particles come 
into contact with each other during the hot press sintering process. For application as a light water reactor nuclear fuel, the TRISO particles have to be uniformly distributed within the FCM nuclear fuel. Power generation efficiency degradation can occur in the areas of non-uniform TRISO particle distribution in the FCM nuclear fuel due to a sharp increase in the internal temperature of the nuclear fuel or uneven output. ${ }^{2)}$ Also, the thermal conductivity of the FCM nuclear fuel can be significantly reduced from the non-uniform distribution of internal TRISO particles. However, the research on the degree of TRISO particle distribution within the FCM nuclear fuel pellet has not been previously carried out.

In this study, TRISO particles containing FCM pellets were fabricated using hot press sintering. The TRISO particles were overcoated with $\mathrm{SiC}$ matrix phase powder to uniformly distribute the embedded TRISO particles. A method to analyze the distribution uniformity of the TRISO particles located in the FCM pellet was proposed. Using the proposed method, the presence of overcoating and the distribution uniformity of the FCM composite fabricated by varying the thickness of the overcoating layer were determined. Through this, FCM composites containing uniformly distributed TRISO particles were fabricated.

\section{Experimental Procedure}

In this study, TRISO powder fabricated using CVD and bSiC powder $(\sim 0.5 \mu \mathrm{m}$, Grade BF17, H. C. Starck H.C, Berlin, Germany) were used to manufacture the $\mathrm{SiC}$ composite ceramic.

The TRISO-coated particles were fabricated through fluidized-bed chemical vapor deposition (FBCVD) in a fluid environment of $\mathrm{ZrO}_{2}$ particles with a diameter of approximately $500 \mu \mathrm{m}$. When the deposition temperature was reached in the reactor, the $\mathrm{ZrO}_{2}$ particles were inserted in the upper part of the reactor under an Ar gas flow environment. Also, since the steady flow state has to be maintained for the particles under an environment where the reacting gas and fluidizing gas are simultaneously supplied, the total flux was varied from 2000 to $3000 \mathrm{sccm}$ to continuously deposit the buffer PyC/IPyC/SiC/OPyC layer when the $\mathrm{ZrO}_{2}$ particles are in a steady flow and the gases used were $\mathrm{C}_{2} \mathrm{H}_{2} /$ $\mathrm{Ar}, \mathrm{C}_{2} \mathrm{H}_{2} / \mathrm{C}_{3} \mathrm{H}_{6} / \mathrm{Ar}, \mathrm{CH}_{3} \mathrm{SiCl}_{3}(\mathrm{MTS}) / \mathrm{H}_{2} / \mathrm{Ar}$, and $\mathrm{C}_{2} \mathrm{H}_{2} / \mathrm{C}_{3} \mathrm{H}_{6} / \mathrm{Ar}$, respectively. The input gas ratio $\left(\mathrm{H}_{2} / \mathrm{MTS}\right)$ was maintained at 50 during the $\mathrm{SiC}$ layer deposition. The coating layers of all the TRISO-coated particles were continuously deposited in a particle flow environment. ${ }^{16)}$

Liquid phase sintering was used to fabricate the FCM pellets containing TRISO. For the sintering aids, 3 wt.\% of $\mathrm{Al}_{2} \mathrm{O}_{3}$ (150 nm, purity 99.9\%, Metal Chem Tech, Haryana, India) $-\mathrm{Y}_{2} \mathrm{O}_{3}(100 \mathrm{~nm}$, purity $99.9 \%$, Metal Chem Tech, Haryana, India) additive $\left(\mathrm{Al}_{2} \mathrm{O}_{3}: \mathrm{Y}_{2} \mathrm{O}_{3}=7: 3\right.$ molar ratio) and 5 wt. $\%$ of nanoscale $\mathrm{SiC}$ powder $(45-55 \mathrm{~nm}$, purity $97.5 \%$, N \& A Materials. Inc., Houston, USA) were used. For each powder, ball milling for $24 \mathrm{~h}$ was conducted using SiC balls
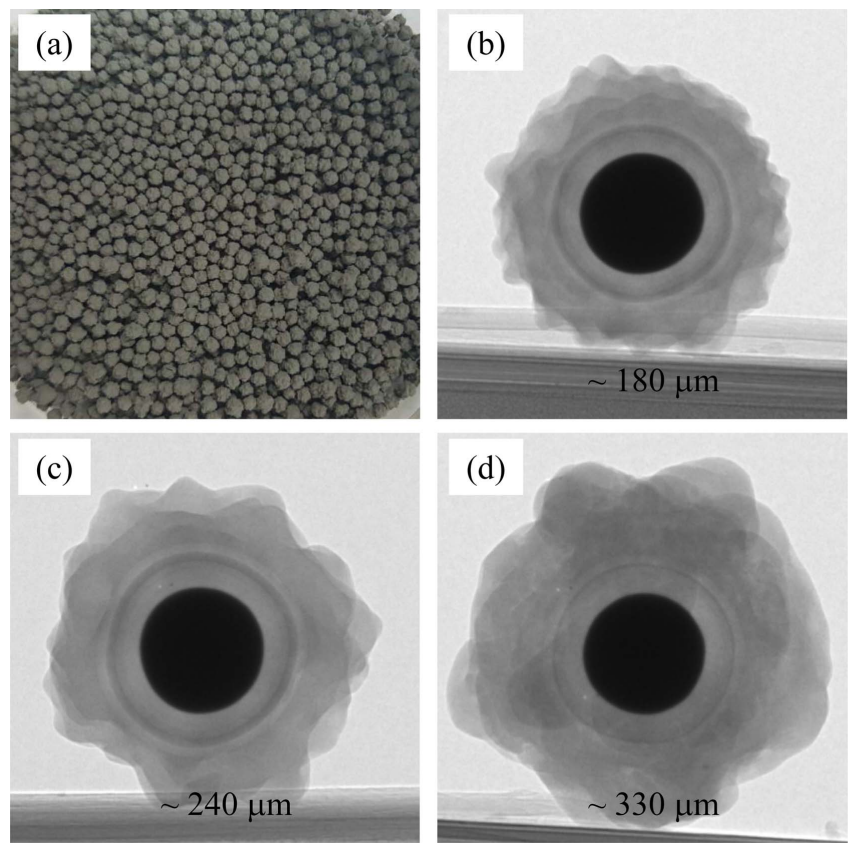

Fig. 1. (a) Overcoated TRISO-coated particles and X-ray radiography images of overcoated TRISO particle with thicknesses of about (a) $180 \mu \mathrm{m}$, (b) $240 \mu \mathrm{m}$, and (c) $330 \mu \mathrm{m}$.

and ethanol as the medium in a polypropylene bottle. After the ball milling, drying and sieving (120 mesh) were conducted. The granulated powder was mixed with the TRISOcoated particles, and the mixed powder was inserted in a graphite sleeve with a diameter of $10 \mathrm{~mm}$ for the sintering of the mixed powder. SiC matrix phase powder was used to overcoat the TRISO particles in order to enhance the TRISO particle distribution. After inserting the TRISO particles in a rotating container, a solvent mixture of $\mathrm{SiC}$ matrix phase powder, ethanol, and water at appropriate ratios was continuously added to establish the overcoating layer with a certain thickness. The weight ratio of the TRISO particle and inserted $\mathrm{SiC}$ matrix phase powder was varied to fabricate overcoating layers of various thicknesses. Fig. 1 shows the overcoated TRISO particles and the overcoated TRISO particles for each thickness. The overcoated TRISO particles with various thicknesses were mixed with the $\mathrm{SiC}$ matrix phase powder and then inserted in the graphite sleeve with a diameter of $10 \mathrm{~mm}$. The FCM pellets were fabricated through hot press sintering under an Ar environment, temperatures of 1800 and $1850^{\circ} \mathrm{C}$, and pressure of 20 $\mathrm{MPa}$.

The density of each pellet was measured using the Archimedes method. X-ray $\mu \mathrm{CT}$ (Skyscan1272, Bruker, Belgium) was used to observe the TRISO coated particle distribution in the FCM pellet. The spatial resolution of the equipment was 2.9 - $13.3 \mu \mathrm{m}$ and the projected radiation images of 0.5 $1.0^{\circ}$ can be collected. For the X-ray, $60 \mathrm{kV}$ and $166 \mu \mathrm{A}$ were used, and the exposure time of 0.5 seconds was used per image. The measurement specimens were pellet shaped 
samples with a diameter of $10 \mathrm{~mm}$ and height of $4-10 \mathrm{~mm}$.

In order to evaluate the TRISO dispersion uniformity within the FCM pellet, X-ray $\mu \mathrm{CT}$ was used to determine the $(x, y, z)$ spatial coordinates of the TRISO particles within the pellet. The radiation images were analyzed to determine the locations and exact number of the TRISO particles, and through this, the volume fraction of the TRISO particles in the FCM pellet was precisely measured. When spherical particles are most uniformly filled in the pellet, the spherical particles have a closed packing FCC structure. In an FCC structure, there are equidistant 12 particles closest to one particle. Based on the FCC structure, the dispersion uniformity index of the TRISO particle in the FCM pellet was set as the average distance of the closest 12 particles based on each TRISO particle and the standard deviation of the average distances for all the TRISO particles. The average distance to the 12 closest particles was expressed as a ratio of the distance between particles under the assumption that the same number of TRISO particles within the FCM pellet are distributed in an ideal FCC structure. When the TRISO particles in a pellet is distributed in an ideal FCC structure, the average value ratio of the distances between each particle (distance ratio) was 1 and the standard deviation of the averages of the distance between each particle (distance standard deviation) was 0 . For the actual pellet, the distance ratio and distance standard deviation can increase due to the particles located on the boundary of the pellet and this case was analyzed in the following chapter.

\section{Results and Discussion}

In the FCM pellet fabrication, overcoating of the TRISO particle exterior was carried out using SiC matrix phase in order to improve the TRISO particle dispersion uniformity. ${ }^{17)}$ The TRISO particle overcoating layer not only enhances the dispersion uniformity but also prevents the direct contact between TRISO particles in the FCM pellet, which can damage the TRISO particle coating layer during the sintering process. Fig. 2 shows the radiation images and the cross section microstructure SEM images of the FCM pellets fabricated through hot press sintering at $1800^{\circ} \mathrm{C}$ and $20 \mathrm{MPa}$ pressure for $3 \mathrm{~h}$ using overcoated and non-overcoated TRISO particles. Figs. 2(a) and (b) show the FCM pellets fabricated using the non-overcoated TRISO particles. The $\mathrm{ZrO}_{2}$ kernel can be observed in the TRISO particle from the X-ray radiation image and the degree of TRISO particle dispersion in the pellet can be observed through the projected image. ${ }^{18)}$ It was observed that the TRISO particles were not evenly distributed in the pellet but concentrated in the lower and central parts and there was an area in the upper portion with no TRISO particles. Also, the cross section SEM imaging showed that there were many TRISO particles in contact with each other. Deformed TRISO particles from the pressing process and particles with damaged TRISO coating layers were observed. Figs. 2(c) and (d) show
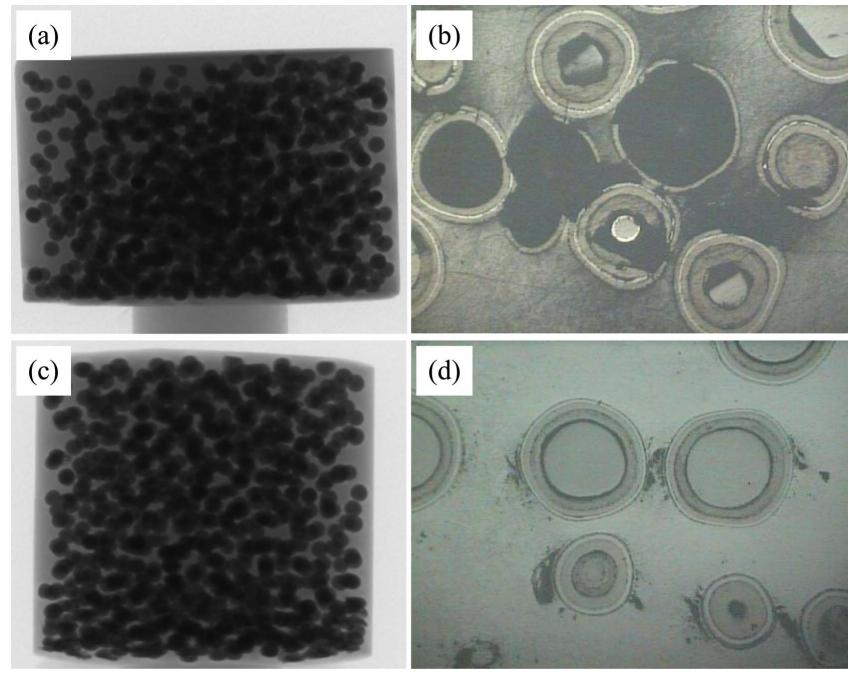

Fig. 2. X-ray radiography image and OM images of FCM sintered pellets (a), (b) without and (c), (d) with application of overcoating to TRISO-coated particles.

the FCM pellets fabricated using the overcoated TRISO particles. The thickness of the overcoating layer was approximately $160 \mu \mathrm{m}$. The X-ray radiation image of the FCM pellet that used overcoated particles showed that the TRISO particles were uniformly distributed for the entire pellet in contrast to the pellet that used non-overcoated particles and areas with no TRISO particles were barely observed. The cross section microstructure image also showed that the TRISO particles were distributed to have consistent distance between the particles so damage of the coating layer did not occur.

While the degree of distribution could be determined approximately through the radiation and cross section microstructure images of each FCM pellet, research on a measure to quantitatively assess the distribution uniformity is lacking. In this study, as shown in Chapter 2, the $(\mathrm{x}, \mathrm{y}, \mathrm{z})$ spatial coordinates of the TRISO particles were identified through $\mu \mathrm{CT}$ followed by calculating the average distance value from each TRISO particle to the closest 12 particles and then the average and the standard deviation of the distance average values for all the TRISO particles in the form of a distribution uniformity index. Table 1 shows the determined distribution uniformity index values for two types of pellets according to the usage of overcoated particles. The distance ratio of the non-overcoated particle applied pellet was 0.996 and the distance ratio of the overcoated particle applied pellet was 1.024 . When the particles are arranged as an ideal FCC structure, the distance ratio has to be 1 but the TRISO particles located on the surface of the pellet have less than 12 closest particles in proximity, and thus the actual distance ratio within the pellet becomes greater than 1. For the two types of pellets, the TRISO particle content in terms of volume ratio was approximately 32 $\sim 35 \%$, and for this case, the distance ratio for the most ideal distribution was calculated to be around $1.10-1.15$ when 
Table 1. Fabrication Conditions, Relative Density and Dispersion Uniformity Index of FCM Pellets Sintered at $1800^{\circ} \mathrm{C}$ and $20 \mathrm{MPa}$ for $3 \mathrm{~h}$

\begin{tabular}{cccccc}
\hline & $\begin{array}{c}\text { Volume ratio of } \\
\text { TRISO particles }\end{array}$ & $\begin{array}{c}\text { Thickness of } \\
\text { overcoating layer }\end{array}$ & $\begin{array}{c}\text { Relative density } \\
(\%)\end{array}$ & $\begin{array}{c}\text { Distance ratio } \\
\text { Distance standard } \\
\text { deviation }\end{array}$ & $\begin{array}{c}\text { Dever } \\
\text { Non-overcoating TRISO }\end{array}$ \\
Overcoating TRISO & $32.9 \%$ & 0 & 99.9 & 0.996 & 0.165 \\
\hline
\end{tabular}

considering the pellet size and TRISO particles located on the surface. It was found that the distance ratio for the overcoating applied pellet increased close to the ideal case. As can be observed in the radiation image, the FCM pellet where the TRISO particles are concentrated in the lower and central parts showed numerous particles in close proximity, resulting in a decrease in the distance ratio. The distance standard deviation of the pellet without overcoating was 0.165 while that of the overcoating applied pellet was significantly decreased to 0.121 . The distance standard deviation is 0 when the particles are uniformly arranged in an ideal FCC structure. As the TRISO particles within the pellet are distributed more sparsely or concentrated in a small area, the average distance value for the closest 12 particles about each TRISO particle changes greatly, thus significantly increasing the standard deviation. Based on the above results, the dispersion uniformity of the TRISO particles in the two pellet types was quantitatively determined. Experimentation was carried out using various fabrication conditions to enhance the TRISO particle dispersion uniformity and the dispersion uniformity improvement was investigated by calculating the dispersion uniformity index for each pellet.

Table 2 shows the calculated dispersion uniformity indices of the FCM pellets according to the overcoating thickness and additional SiC powder ratio. Specimens C1 - C4 were FCM pellets with TRISO volume ratios of $30-40 \%$ fabricated at $1800^{\circ} \mathrm{C}$ and $20 \mathrm{MPa}$ for $1 \mathrm{~h}$ using the two overcoating thickness conditions of approximately $60 \mu \mathrm{m}$ and 160 $\mu \mathrm{m}$. For the $\mathrm{C} 1$ and $\mathrm{C} 3$ specimens with TRISO volume ratios of around $30 \%$, the distance ratio and distance standard deviation both increased as the overcoating thickness was increased. For the $\mathrm{C} 2$ and $\mathrm{C} 4$ specimens with TRISO volume ratios of around $40 \%$, the distance ratio increased while the distance standard deviation decreased as the overcoating thickness increased. When the overocating thickness is less than $160 \mu \mathrm{m}$, it can be considered that the overcoating thickness does not have a significant impact on the dispersion uniformity of the TRISO particles in the FCM pellet.

Specimens CA1 - CA4 were FCM pellets fabricated at $1850^{\circ} \mathrm{C}$ and $20 \mathrm{MPa}$ for $3 \mathrm{~h}$ using TRISO particles with overcoating thicknesses of 180,240 , and $330 \mu \mathrm{m}$. The specimens were fabricated by varying the TRISO volume ratios from $30 \%$ to $50 \%$. When the pellet is fabricated using only overcoated TRISO particles, FCM pellets with a specified volume ratio according to the overcoating thickness can be manufactured. Also, FCM pellets of specific volume ratio can be fabricated by mixing the overcoated TRISO particles with additional SiC matrix phase powder. Specimens CA2, CA3, and CA4 were FCM pellets fabricated using overcoated TRISO particles with thicknesses of 180, 240, and $330 \mu \mathrm{m}$ while the volume ratios were $33.5,40.7$, and $50.2 \%$. Specimen CA1 was an FCM pellet with a volume ratio of approximately 30\% using $240 \mu \mathrm{m}$ thickness overcoated TRISO particles and additional SiC matrix phase powder mixture. Table 2 shows the mass ratios of the overcoated TRISO particles and additionally used SiC matrix phase powder. The additional SiC matrix phase powder mixed CA1 specimen had a distance ratio of 1.05 and distance standard deviation of 0.127 . The CA2, CA3, and CA4 specimens that only used overcoated TRISO particles without additional SiC matrix phase powder mixture showed distance ratios of $1.101,1.089$, and 1.098, respectively, and dis-

Table 2. Fabrication Conditions, Weight Ratio of Additional SiC Powder, Relative Density and Dispersion Uniformity Factor of FCM Pellets Sintered at $1800^{\circ} \mathrm{C}$ and $20 \mathrm{MPa}$ for $1 \mathrm{~h}(\mathrm{C} 1-\mathrm{C} 4)$ and Sintered at $1850^{\circ} \mathrm{C}$ and $20 \mathrm{MPa}$ for $3 \mathrm{~h}(\mathrm{CA} 1-4)$

\begin{tabular}{ccccccc}
\hline & $\begin{array}{c}\text { Volume Ratio of } \\
\text { TRISO particles }\end{array}$ & $\begin{array}{c}\text { Thickness of } \\
\text { overcoating } \\
\text { layer }\end{array}$ & $\begin{array}{c}\text { Weight ratio of additional } \\
\text { SiC powder to overcoated } \\
\text { TRISO }\end{array}$ & $\begin{array}{c}\text { Relative } \\
\text { density (\%) }\end{array}$ & $\begin{array}{c}\text { Distance } \\
\text { ratio }\end{array}$ & $\begin{array}{c}\text { Distance } \\
\text { standard deviation }\end{array}$ \\
\hline C1 & $30.4 \%$ & 60 & 1.40 & 94.2 & 1.013 & 0.127 \\
C2 & $40.5 \%$ & 60 & 0.78 & 94.0 & 1.037 & 0.117 \\
C3 & $33.3 \%$ & 160 & 0.80 & 97.4 & 1.027 & 0.139 \\
C4 & $40.7 \%$ & 160 & 0.33 & 89.7 & 1.051 & 0.109 \\
CA1 & $29.9 \%$ & 240 & 0.53 & 99.6 & 1.050 & 0.127 \\
CA2 & $33.5 \%$ & 330 & 0 & 97.8 & 1.101 & 0.082 \\
CA3 & $40.7 \%$ & 240 & 0 & 97.2 & 1.089 & 0.083 \\
CA4 & $50.2 \%$ & 180 & 0 & 98.4 & 1.098 & 0.067 \\
\hline
\end{tabular}



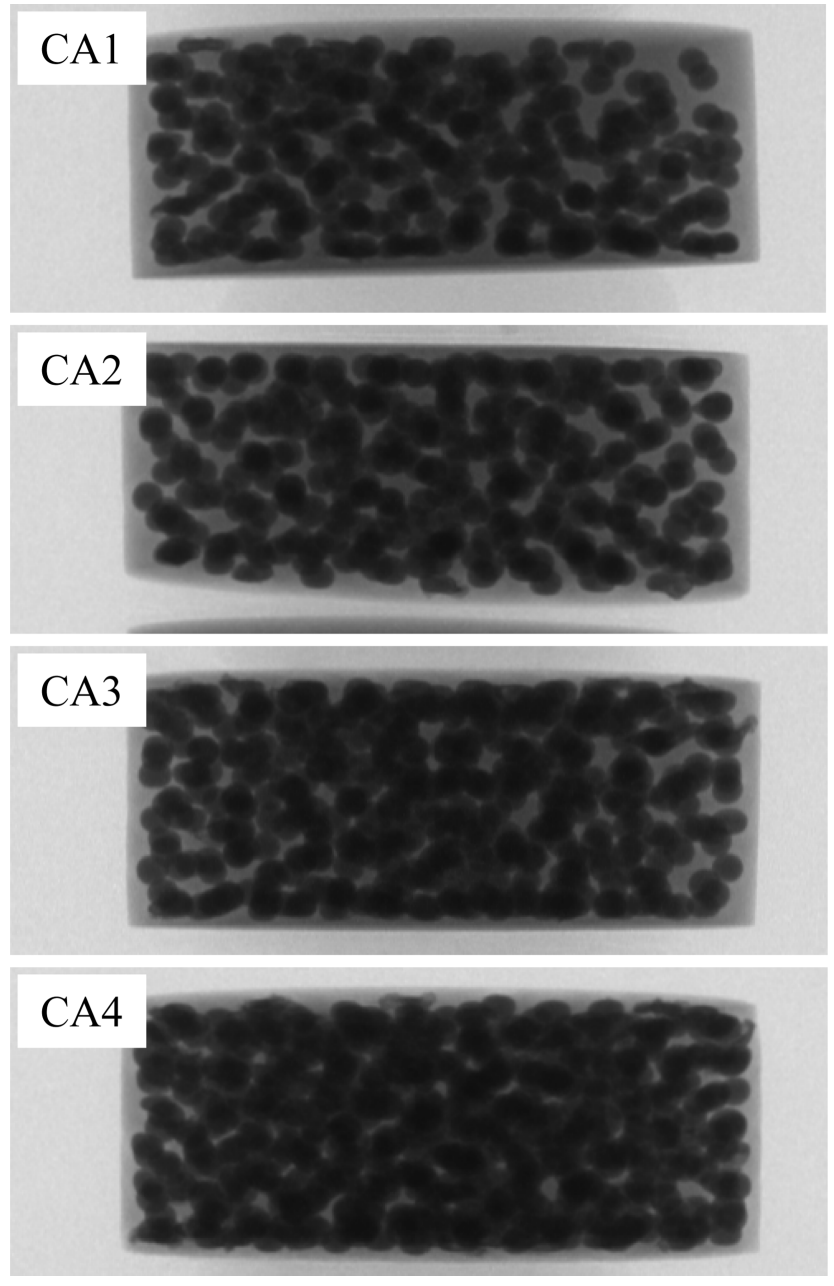

Fig. 3. X-ray radiography images of FCM pellets with only overcoated TRISO particles (CA2-4); overcoated TRISO particles and additional SiC matrix powder (CA1).

tance standard deviations of $0.082,0.083$, and 0.067 , respectively. The specimens that only used overcoated TRISO particles without additional matrix phase powder showed high dispersion uniformity regardless of the overcoating layer thickness and TRISO particle volume ratio. In order to fabricate FCM pellets of uniformly dispersed TRISO particles, determining the overcoating layer thickness appropriate for the desired volume ratio needs to be carried out. When the large amounts of additional SiC matrix phase powder is mixed, the dispersion uniformity of the pellets may be worse due to the phenomenon where the matrix phase exists in concentrations, but a consistent distribution according to the overcoating layer thickness can be attained when only using overcoated TRISO particles. Fig. 3 shows the X-ray radiation images of the CA specimens. The specimens CA2 - CA4 mostly showed even distributions from the projected images. For specimen CA1, sparse distributions of TRISO particles were observed in the upper left side. This result was thought to be due to the concentration of the additional $\mathrm{SiC}$ matrix phase powder, and as a result it was estimated that the TRISO particle dispersion unifor- mity would be degraded.

For specimens CA1 and CA2 with similar amounts of TRISO volume ratio, the CA2 specimen without the additional $\mathrm{SiC}$ matrix phase powder mixture showed a density that was lower than that of the CA1 specimen with an additional SiC matrix phase powder mixture to some extent. The density of the FCM pellet fabricated only using overcoated TRISO particles can decrease due to the voids between the overcoated TRISO particles with a diameter of approximately $1.2-1.5 \mathrm{~mm}$. In order to fabricate FCM pellets of uniform TRISO particle distribution, it is important that sintering is carried out only using overcoated TRISO particles, but it was thought that efforts to modify the sintering condition or mix an appropriate amount of additional $\mathrm{SiC}$ matrix phase powder are necessary to improve the pellet density.

\section{Conclusions}

FCM pellets containing TRISO particles were fabricated using hot press sintering to analyze the distribution of the embedded TRISO particles. X-ray $\mu \mathrm{CT}$ was used to determine the location coordinates of the TRISO particles within the FCM pellets. When the embedded particles dispersed in an FCC structure was assumed to be the structure with the most uniform distribution, the distance ratio and distance standard deviation between each TRISO particle and its closest 12 particles were calculated to determine the dispersion uniformity index value. The TRISO particles were overcoated on the exterior with $\mathrm{SiC}$ matrix phase powder in order to improve the dispersion uniformity and prevent the direct contact of TRISO particles with each other during the FCM pellet sintering. The dispersion uniformity index values for the specimens fabricated using non-overcoated TRISO particles and specimens fabricated using overcoated TRISO particles revealed that the overcoating applied specimens showed both outstanding distance ratio and distance standard deviation. The dispersion uniformity was also observed through the X-ray radiation and cross section microstructure images. The TRISO particle dispersion uniformity was evaluated according to the overcoating layer thickness and whether the additional $\mathrm{SiC}$ matrix phase powder was mixed. Variation of the overcoating layer thickness did not show a significant impact on the embedded particle dispersion. The FCM specimen fabricated only using overcoated TRISO particles without additional SiC matrix phase powder mixing showed the highest dispersion uniformity. Various FCM specimens with TRISO particle volume ratios of $33.5 \%-50.2 \%$ for uniform distribution according to the overcoating layer thickness were fabricated.

\section{Acknowledgments}

This work was supported by the National Institute of Energy Technology Evaluation and Planning (KETEP), funded by the Korean government (MOTIE) (No. 20171510101990). 


\section{REFERENCES}

1. L. L. Snead, K. A. Terrani, F. Venneri, Y. Kim, J. E. Tulenko, C. W. Forsberg, P. F. Peterson, and E. J. Lahoda, "Fully Ceramic Microencapsulated Fuels: A Transformational Technology for Present and Next Generation Reactors-Properties and Fabrication of FCM Fuel," Trans. Am. Nucl. Soc., 104 668-70 (2011).

2. K. A. Terrani, L. L. Snead, and J. C. Gehin, "Microencapsulated Fuel Technology for Commercial Light Water and Advanced Reactor Application,” J. Nucl. Mater., 427 [1-3] 209-24 (2012).

3. J.-H. Chun, S.-W. Lim, B.-D. Chung, and W.-J. Lee, "Safety Evaluation of Accident Tolerant FCM Fueled Core with SiC-Coated Zircaloy Cladding for Design-Basis Accidents and Beyond DBAs," Nucl. Eng. Des., 289 287-95 (2015).

4. D. R. Olander, "Nuclear Fuels - Present and Future," J. Nucl. Mater., 389 [1] 1-22 (2009).

5. W.-J. Kim, S. M. Kang, K. H. Park, A. Kohyama, W.-S. Ryu, and J. Y. Park, "Fabrication and Ion Irradiation Characteristic of SiC-Based Ceramics for Advanced Nuclear Energy System (in Korean)," J. Korean Ceram. Soc., 42 [8] 575-81 (2005).

6. Y. Katoh, T. Nozawa, L. L. Snead, K. Ozawa, and H. Tanigawa, "Stability of $\mathrm{SiC}$ and Its Composites at High Neutron Fluence," J. Nucl. Mater., 417 [1-3] 400-05 (2011).

7. G. R. Hopkins and R. J. Price, "Fusion Reactor Design with Ceramics," Nucl. Eng. Des./Fusion, 2 [1] 111-43 (1985).

8. L. L. Snead, K. A. Terrani, Y. Katoh, C. Silva, J. J. Leonard, and A. G. Perez-Bergquist, "Stability of SiC-Matrix Microencapsulated Fuel Constituents at Relevant LWR Conditions," J. Nucl. Mater., 448 [1-3] 389-98 (2014).

9. B. W. Lin, M. Imai, T. Yano, and T. Iseki, "Hot-Pressing of $\beta$-SiC Powder with Al-B-C Additives," J. Am. Ceram. Soc., 69 [4] C67-68 (1986).
10. B. R. Zhang, F. Marino, and M. Ferraris, "Liquid-Phase Hot-Pressing and WC Particle Reinforcement of SiC-Si Composites,” J. Eur. Ceram. Soc., 14 [6] 549-55 (1994).

11. K. Yoshida, Budiyanto, M. Imai, and T. Yano, "Processing and Microstructure of Silicon Carbide Fiber-Reinforced Silicon Carbide Composite by Hot-Pressing," J. Nucl. Mater., 258-63 1960-65 (1998).

12. S. Dong, Y. Katoh, and A. Kohyama, "Preparation of $\mathrm{SiC} /$ SiC Composite by Hot Pressing, Using Tyranno-SA Fiber as Reinforcement," J. Am. Ceram. Soc., 86 [1] 26-32 (2003).

13. K. A. Terrani, J. O. Kiggans, Y. Katoh, K. Shimoda, F. C. Montgomery, B. L. Armstrong, C. M. Parish, T. Hinoki, J. D. Hunn, and L. L. Snead, "Fabrication and Characterization of Fully Ceramic Microencapsulated Fuels," J. Nucl. Mater., 426 [1-3] 268-76 (2012).

14. H.-G. Lee, D. J. Kim, J. Y. Park, and W.-J. Kim, "Sintering and Characterization of SiC-Matrix Composite Including TRISO Particles (in Korean)," J. Korean Ceram. Soc., 51 [5] 418-23 (2014).

15. H.-G. Lee, D. J. Kim, S. J. Lee, J. Y. Park, and W.-J. Kim, "Thermal Conductivity Analysis of SiC Ceramics and Fully Ceramic Microencapsulated Fuel Composites," Nucl. Eng. Des., 311 9-15 (2017).

16. J. G. Kim, E.-S. Kum, D. J. Choi, S. S. Kim, H. L. Lee, Y. W. Lee, and J. Y. Park, "A Study on the CVD Deposition for SiC-TRISO Coated Fuel Material Fabrication (in Korean)," J. Korean Ceram. Soc., 44 [3] 169-74 (2007).

17. K. A. Terrani, J. O. Kiggans, C. M. Silva, C. Shih, Y. Katoh, and L. L. Snead, "Progress on Matrix SiC Processing and Properties for Fully Ceramic Microencapsulated Fuel Form,” J. Nucl. Mater., 457 9-17 (2015).

18. G. Y u, Y. Du, X. Xiang, Y. Liu, Z. Li, and X. Wang, "3D Nondestructive Visualization and Evaluation of TRISO Particles Distribution in HTGR Fuel Pebbles Using ConeBeam Computed Tomography," Sci. Technol. Nucl. Install., 20173857075 (2017). 